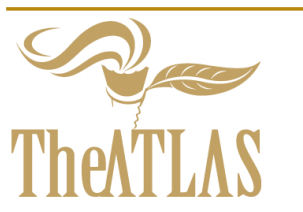

\title{
Transdisciplinarity: Dilemmas, Elasticity in Perspectives, and Anxiety-the Case of Integrated Surveys
}

W.H. Erik de Man, Retired, formerly with the International Institute for Geo-Information Science and Earth Observation (ITC), Enschede, The Netherlands; Email:deman@itc.nl

Received 25 March, 2019; Revised 26 June, 2019, Accepted 30 June, 2019

Copyright (C)2019 W.H. Erik de Man. This is an open access article distributed under the Creative Commons Attribution License (https://creativecommons.org/licenses/by/4.0/), which permits unrestricted use, distribution, and reproduction in any medium, provided the original work is properly cited.

Available online 3 July, 2019 at www.atlas-journal.org, doi: 10.22545/2019/0125

 he aim of the paper is to contribute to the ongoing discourse of transdisciplinarity by providing a case study in the development some fifty years ago of 'integrated surveys'-integrated, multi-disciplinary resource studies for developmentas an application of transdisciplinarity avant la lettre. Lessons from integrated surveys suggest that transdisciplinarity would require 'elasticity in perspectives'; the ability to accommodate dilemmas of conflicting perspectives at shared problem situations. This common ground resembles the 'included middle' in transdisciplinarity as proposed by Nicolescu. Looking from rather than disciplinary looking at the problem may create an emergent understanding of its 'reality'. The case history of integrated surveys also suggests that when research gets more transdisciplinary, researchers enter unfamiliar disciplinary grounds which could create uncertainty and even anxiety about their identity, legitimacy, relevance and stature. Finally, the paper argues that transdisciplinarity is not necessarily rigorous. Its rigor is dependent on the specific problem situation under investigation.

Keywords: Dilemmas, disciplinary perspectives, integrated surveys, knowledge integration, transdisciplinarity, levels of reality, included middle, disciplinary anxiety.

\section{Introduction}

This paper is about the field of transdisciplinarity and in particular how it develops as an open, empirically based body of knowledge in helping our understanding of what the world actually is and how to deal with it. Transdisciplinarity is generally placed at the juxtaposition between science and society. In the views of Hirsch Hadorn [1] and Klein [2], and their respective co-authors, it addresses the need for integrated knowledge from a variety of diverse perspectives in societal problem solving regarding complex societal concerns. Some have claimed that 
this integration of knowledge can be achieved only through the methods developed in the natural sciences (e.g. Wilson [3]). But such view would simply mean a total takeover by the natural sciences and their reductionist approach as others have noticed. For instance Costanza [4] sees a pluralistic and transdisciplinary approach emerging "one in which the natural and social sciences and the humanities all contribute equitably". In a similar vein, Gibbons, Nowotny and their co-authors [5], [6] propose a "new production of knowledge" that "operates within a context of application in that problems are not set within a disciplinary framework. It is transdisciplinary rather than mono- or multidisciplinary. It is carried out in non-hierarchical, heterogeneously organised forms which are essentially transient [and] not being institutionalised primarily within university structures".

Following others (e.g. [7], [8], [9]), I do not view transdisciplinarity as a unified body of concepts and approaches nor as a coherent theory and methodology. Nevertheless, some general consensus can be found and fruitful concepts are offered. Jahn et al. [7] describe transdisciplinarity as a research approach and not a theory, methodology or institution. Some see transdisciplinarity simply as joint work of scientists and individuals from practice (e.g. Seidl [10]) while others see it primarily as (action) research beyond disciplinarity and involving stakeholders who are not academics (e.g. Pohl et al. [8]). In this sense, transdisciplinary research is understood by some as part of a social process with strong elements from the bottom up, as well as related to the common good as being the opposite of private interests [1]. Here, I follow Nicolescu [11] in that transdisciplinarity simply "concerns that which is at once between the disciplines, across the different disciplines, and beyond all disciplines" (my italics).

From these brief introductory notes it seems to me that transdisciplinarity is essentially open and inclusive whereas (academic) disciplinarity delineates into closed systems [11] as the term discipline generally refers to a set of coherent intellectual values and constraints like focus of study, rhetoric, paradigms, rationalities, and methods, embraced by the members of a scientific-or any-community (e.g. [12], [13], [14]). Therefore, the field of transdisciplinarity likely faces the dilemma of how it can matters scientifically while avoiding the risk of becoming an established, academic discipline by itself-the dilemma of trans-

\section{disciplinarity.}

The aim of the paper is to contribute to the discourse of transdisciplinarity by providing a case study in the development of 'integrated surveys' as this concept emerged some fifty years ago-an application of transdisciplinarity avant la lettre. Here, the term 'integrated surveys' refers to integrated, multidisciplinary resource studies for development. In particular, I intend to show how transdisciplinarity can help in a better understanding of this case study in retrospect, and at the same time can learn from it. The case history is the development of 'integrated surveys' at the former International Training Centre for Aerial Survey (ITC) in the Netherlands during the 1960s and 70s. [At present, the ITC is as the Faculty of Geo-Information Science and Earth Observation part of the University of Twente, Enschede, The Netherlands.]

In the remainder of this paper I first sketch the idea of 'integrated surveys' as it was developed and put into practice at the ITC and some of the lessons that can be drawn from it (Section 2). A major lesson is that the production of integrated knowledge likely encounters dilemmas because of mutually incompatible perspectives between different actors on what the world actually is and how to deal with it. This requires 'elasticity in perspectives' to reconcile their incompatibilities as Luning [15] put it. Then, I review integrated surveys through the lens of transdisciplinarity (Section 3) and argue that this elasticity in perspectives is similar to finding reconciliation between pairs of mutually exclusive contradictories through the 'included middle' in transdisciplinarity-as understood by Nicolescu [11]. In the next section, I explore what practical lessons transdisciplinarity could take from the case history of integrated surveys (Section 4). First, I argue that the 'included middle' in transdisciplinarity is situated at the 'level of reality' of the challenges and problems under investigation and can be found as a shared and time and again negotiated and renegotiated understanding between the various actors. But this would require a change from disciplinary looking at these problems into looking from them. After that, I argue that transdisciplinarity is about social processes where different actors are involved in finding reconciliation between their mutually incompatible perspectives. It requires between the actors a culture of openness, of dialogue and of mutual learning. Consequently, when research gets more 
transdisciplinary, researchers move away from their familiar, disciplinary background. This could create uncertainty-if not anxiety-for researchers about their identity, legitimacy, relevance and stature. Finally, I discuss (in Section 5) what these findings and arguments set forth in the paper could possibly mean for the transdisciplinarity discourse.

\section{Integrated Surveys: a Social Process Requiring Elasticity in Perspectives}

The period immediately after the Second World War witnessed a marked growth in the application of aerial surveys and photo interpretation in resource studies for development. Against this backdrop, the ITC was created in the early 1950s, as a Netherlands contribution to international technical assistance at the request of the Economic Development and Stability Division of the United Nations [16]. Formally established in 1950, the ITC commenced its activities in September, 1951 with Professor Willem Schermerhorn-an internationally esteemed pioneer in aerial surveys and photogrammetry- as its founder and first Rector. Initially, the ITC provided training in photogrammetry, aerial photography, and aerial photo interpretation and inventory in the fields of geology, soil sciences, and forestry [16], [17].

The development of the ITC over the next ten years or so brought the need to accommodate a continuously increasing range of diverse disciplinary applications of aerial and aerospace surveys [17], [18] At the same time, the need for integrated studies was generally felt internationally and reflected changing views on development from the large, technical infrastructure and irrigation projects of the late 1940s to an understanding that problems of development are so complex and multi-dimensional that in addressing them, an integrated approach is needed (see also [19], [20]). It was also recognized that the need for integrated resource studies brought a need for further development of methods of and training in integrated surveys as well.

Following recommendations of the UNESCO conference on aerial surveys and integrated studies in 1964, the ITC-UNESCO Centre for Integrated Surveys was established as attachment to the ITC [21]. The Centre started its activities in 1965. Together with the Centre, a full Department of Integrated Sur- veys was also created at the ITC. [For an overview of practices, methodology and reviews of integrated surveys worldwide at the time, see the proceedings of the UNESCO-conference [22]. In particular, the methodology of integrated surveys as developed by the Commonwealth Scientific and Industrial Research Organization (CSIRO), Australia, is noteworthy [23].]

\subsection{Development of Integrated Surveys at the ITC}

Over a period of almost two decades, the ITCUNESCO Centre further developed the concept of integrated surveys with the fieldwork of its regular post-graduate training course as a major vehicle. Typically, such fieldwork was carried out as integrated surveys by a team composed of course participants and staff of the Department and responding to terms of reference given by a regional (government) authority.

The development of the concept of integrated surveys went in stages. Initially the concept of integrated surveys was predominantly survey-oriented. Vink, for example, understood integrated surveys as the coordinated preparation, execution and evaluation of different topographical and resource surveys to obtain a comprehensive picture "of the situation of man in his natural environment" [24]. Likewise, Mohrmann saw an integrated survey as "any survey in which data of different kind, coming from different actors, have to be gathered, coordinated and considered in such a way that a coherent result may be expected" [25]. Bakker [26] noticed three trends in integrated surveys; (1) teamwork by specialists to carry out the survey for a common objective with an optimum of efficiency, (2) synthesis of related disciplinary descriptions, and, consequently (3) the emergence of specialized generalists to take care of these general and common activities in integrated surveys-as a discipline in its own right. But as Nossin observed, it was also realized that achieving collaboration may easily be hampered by the difficulty that many scientists and technical specialists are convinced of the supreme importance of their own specialization and often largely ignorant of the activities and interests of other fields which must also contribute to the project [27].

In the early 1970s, the concept of integrated surveys expanded towards planning and decision making. For example, Schulze understood integrated surveys as including "all activities related to col- 
lection, analysis, and interpretation of all kinds of information needed for the formulation of concrete action programmes for development purposes, as well as the formulation of such programmes (or their alternatives) themselves" [28]. In a similar vein, Van den Broek [29] distinguished between "horizontal integration" and "vertical integration". Whereas the former refers to the combination of different disciplinary surveys as efficiently as possible, the latter essentially includes the synthesis of these surveys oriented towards planning and decision making. The expansion into two-dimensional integration added considerably to the complexity of integrated surveys as Nossin noticed. The needed coherence in this dynamic system of two-dimensional integration could be achieved by continuous mutual adaptation of survey results and objectives [27].

The next stage in its development brought the concept of integrated surveys into the realm of deliberative public policy analysis (see also [30]). For example, the terms of reference for the fieldwork of the post-graduate training course in 1975, given by the Gouvernorate of Sousse (Tunisia), were to provide the Gouvernorate with various development alternatives, based on investigations of land, water and human resources, and to determine their consequences in terms of employment and in economic terms (gross value added) in 1986-the end of the next 10-year period [31]. Preliminary examination identified which investigations were needed and the survey team was split into task groups accordingly. A powerful method to facilitate integration of such investigations was for each group to ask and obtain from the other groups as much information as needed and as possibly could be collected by them and, in return, to provide the other groups with as much information as required for the execution of their tasks-the method of the "to's-and-from's" [32]. Because these transactions were discussed within the entire survey team, a shared understanding could emerge of the challenges and problems that were under investigation. During the survey, a variety of development alternatives were identified and projected to the year 1986. These projections were viewed as optimization problems-the optimal use of scarce resources in terms of employment and in terms of economic growth respectively. In the projections, use was made of a simple linear programming model. Its relative simplicity allowed the policy makers to understand the assumptions and limitations of the results and therefore to appreciate the projections of the different development alternatives more than being confronted with once-and-for-all answers [33]. As such, it supported deliberation in policy analysis.

\subsection{The Centre Became a Dormant Facility}

The combination of the ITC-UNESCO Centre for Integrated Surveys and the ITC Department of Integrated Surveys certainly contributed to the development of the concept of integrated surveys and its promotion outside the ITC. At the same time, however, it was not fully integrated within the ITC let alone bringing the integration of its various disciplinary departments as was initially expected (for instance by Schermerhorn [17]). Some claim that this was partly because "researchers arrogantly thought that they were the only people with the right research design" [34].

Not surprisingly therefore, several interdisciplinary courses emerged within the ITC as collaboration between existing disciplinary departments like, for example, the course on photo-interpretation for rural surveys as collaboration between the disciplines of agriculture, rangeland-ecology and rural geography [35]. Unlike the Integrated Survey course, this Rural Survey course dealt not with 'total project survey', but was limited to some important aspects of any survey project for development planning, especially land evaluation itself. Apparently, such interdisciplinary collaboration provided within the ITC a more attractive alternative for the broader concept of integrated surveys as this was developed by the Centre [36].

With the appointment of the Professor of Survey Integration for Development in 1982, the name of the Department changed into Department of Survey Integration as well. Subsequently and with the continuing reorganization within ITC, the Department became the Division of Social Sciences and the ITCUNESCO Centre gradually slipped into a dormant facility. Interestingly, however and almost twenty years later, Van der Veen [34] made an explicit reference to the history of the Centre in his inaugural address as Professor of Governance and Spatial Integrated Assessment at the ITC. He saw this as an "opportunity to work on integrated surveys (as it was called in 1964)". 


\subsection{Elasticity in Perspectives-Looking from Rather than at the Problem}

In my opinion, this brief account clearly shows the development of integrated surveys from, initially, the combination of (geospatial) knowledge from different sources as efficiently as possible to the synthesis of this knowledge oriented towards decisionmaking processes regarding concrete societal challenges and problems. It also shows that integrated survey projects are essentially social processes with interacting actors. In other words, these projects have their social life. In particular, it shows a potentially problematic relation between researchers in integrating surveys and those in the established academic (disciplinary) fields. Finally, it suggests the major challenge for such complex, two-dimensional (horizontal and vertical) integration, succinctly described by Luning [15] as "survey integration requires elasticity in perspectives". Integrated surveys are not limited to academics and generally include planners and decision makers, data collectors and analysts, and often concerned citizens as well. They all must work together but their collaboration is easily constrained by differences in perspectives coming from differences in disciplinary background, differences in understanding knowledge (like practical versus scientific, context-invariant versus context-dependent), and differences in the perception and understanding of the problem situation at hand as well as of possible interventions. Elasticity in perspectives, therefore, refers to the ability of an actor to accommodate conflicting perspectives of others. Or, as Luning has put it, "we must strive for objective observation of reality, unhindered by disciplinary preoccupation" [15]. In this respect, the domain of integrated surveys is between, across, and beyond established disciplines.

But elasticity in perspectives might well go beyond the accommodation of conflicting perspectives on what the world actually is and how to deal with it. Recall the negotiation method of the 'to's-andfrom's' between different groups of disciplinary actors to facilitate integration as mentioned before. Because this method was applied not just as oneto-one transactions between disciplinary groups but also as a vehicle for joint learning, a shared understanding could emerge of the reality of the problem situation under investigation-in the words of Luning: "unhindered by disciplinary preoccupation". Here, it is important to recognize that these problem situations ultimately matter not so much for their scientific appeal but for their impact-for what they afford in human activity, or not (see also [37], [38], [39]). Therefore, these problem situations could be regarded as 'actors' as well. For that reason, it seems to me that elasticity in perspectives changes the direction of perspective from disciplinary looking at these situations into looking from them as if one were looking through their eyes.

\section{Looking at Integrated Surveys through the Lens of Transdisciplinarity}

In this section I will look at integrated surveys as it was outlined before, through the lens of transdisciplinarity. In particular, I want to know if this might lead to a better understanding of the required 'elasticity in perspectives'. For it seems to me that this notion resembles Nicolescu's description of transdisciplinarity in that it concerns that which is at once between the disciplines, across the different disciplines, and beyond all disciplines [11]. But before dealing with the notion of elasticity in perspectives, I think we first need to have a closer look at the very reasons why this elasticity is required-the issue of conflicting and even incompatible perspectives on shared problem situations.

\subsection{Incompatible Perspectives: Dilemmas in the Integration of Knowledge}

The term perspective as used throughout the paper, refers to a pervasive perception of reality and is akin to the idea of Geertz' "world-view"-the picture people have of the way things actually are, their concept of nature, of self, of society; their most comprehensive ideas of order [40]. Perspectives-or world-views for that matter-are both selective and subjective because different actors not only view and perceive the world through different lenses but perspectives also reflect their values such as interests and believe. Moreover, a particular perspective or view of reality brings about its own subjective logic and rationality as is suggested by Thomas' classic adage: "If men define situations as real, they are real in their consequences" [41]. This may explain for example, different responses at different administrative levels to shared problematic environmental conditions. Citizens may understand and perceive various risks-like flooding, earthquakes, health hazards, and 
unemployment-in relation to their everyday life and seem to integrate them into their livelihood at the neighbourhood level, whereas these different risks are generally dealt with separately through specialised agencies at the higher administrative levels (see also [42]).

Conflicting values between actors, therefore, may easily result in mutually incompatible perspectives on the 'reality' of a concrete problem situation or, in other words, conflicting realities between these actors. This can be illustrated by the NIMBY (not in my backyard) syndrome-the bureaucratic reality of most governments that is based on standardization and efficiency in order to simplify state functions versus the reality of citizens that hinges on the uniqueness and nuances of their everyday life and livelihood as Scott noticed [43]. Incompatible perspectives create dilemmas in the integration of knowledge-the need to choose between them. Because one cannot give preference a priori to one perspective over the other, one has to acknowledge the 'right to exist' of each of these perspectives, all of which could contribute equally. Ignoring it may have erroneous consequences in the form of biases in problem solving regarding complex societal concerns that are visible in the future only (see also [43]).

Following Rittel and Webber [44], dilemmas are inherently "wicked" problems in that they cannot be solved definitively but "must be re-solved; over and over again". [For reasons of clarity I use the term dilemma not in its restricted meaning of only two mutually exclusive alternatives but actually including tri- or other multi-lemmas as well.]

Dilemmas will seriously add to the complexity of the integration of knowledge from a variety of diverse perspectives. But instead of capturing and controlling this complexity, the challenge becomes to acknowledge multiple realities shaped by different and heterogeneous actors with diverse and often incompatible views and understanding on what the world actually is and how to deal with it as Hilhorst noticed [45]. In other words, the challenge in dealing with such dilemmas is to continuously accommodate mutually incompatible perspectives on reality of others and to find a common ground between, across and beyond them-over and over again.

\subsection{Elasticity in Perspectives: Temporary Finding a Middle Ground between Incompatible Perspectives-the Included Middle}

Elasticity in perspectives in integrated surveys-or in the integration of knowledge in general-addresses the need to accommodate incompatible perspectives on what the world actually is and how to deal with it. It seems to me that these incompatibilities of perspectives correspond to some extent to what Nicolescu [11] calls 'different levels of reality' in transdisciplinarity: "a set of systems that are invariant under certain laws. For example, quantum entities are subordinate to quantum laws, which depart radically from the laws of the macro-physical world. That is to say that two levels of Reality are different if, while passing from one to the other, there is a break in the applicable laws and a break in fundamental concepts (like, for example, causality)". In my opinion, however, the integration of knowledge from a variety of diverse perspectives regarding complex societal concerns needs a somewhat broader and more inclusive description of level of reality. This is especially the case when knowledge from the natural sciences needs to be integrated with knowledge from the social sciences and humanities. Whereas the explanatory and predictive theory seems to be the ideal and hallmark of the former, the particular and the situational dependent are emphasized in the latter over the universal and over rules [46]. Therefore, in the paper I assume that a phenomenon or event can be viewed from-or related to-different levels of reality each having its own laws, logics and/or rationalities. The difference in understanding and perception of various risks between various actors as this was mentioned before, illustrates this point. Although the city government and its local communities share the same events, from their different levels of reality these events are perceived differently. But it must be emphasised, however, that the idea of 'levels of reality' in transdisciplinarity is by no means necessarily hierarchical or organizational although these examples may seem to suggest otherwise. As Nicolescu explains, "many disciplines coexist at the same level of Reality even if they correspond to different levels of organization. For example, Marxist economy and classical physics belong to one level of Reality, while quantum physics and psychoanalysis belong to another level of Reality" [11].

In terms of levels of reality, dilemmas are the need 
to choose between two contradictory possibilitieswhat is possible or desired at one level of reality is impossible or undesirable at another and vice versa. (Again, the NIMBY syndrome illustrates this point.) In the classical idea of a single level of reality, contradictions and dilemmas cannot be solved definitively. Assertions A and non-A cannot be true at the same time because there is no middle ground between them. Nicolescu refers to this as to the "axiom of the excluded middle" [11]. But in his view, transdisciplinarity not only acknowledges that contradictions occur at specific levels of reality as mutually exclusive opposites. It also assumes that these contradictions can be reconciled at a different (third) level of reality-the "axiom of the included middle" as he refers to it [11]. But this reconciliation is likely also temporary but now for a different reason than with solving dilemmas. Because, while reconciling pairs of contradictories, "it inevitably leads, under the joint pressure of theory and experience, to the discovery of new pairs of contradictories, situated at new levels of Reality" [47].

Looking through the lens of transdisciplinarity, it seems to me that the required elasticity in perspectives in integrated surveys has much in common with finding this 'included middle'. Therefore, the concept of elasticity in perspectives would define in my opinion the identity of integrated surveys as transdisciplinary avant la lettre. Understood as finding the 'included middle', we may become aware that also 'elasticity in perspectives' as the ability of actors to accommodate conflicting perspectives of others in integrated surveys, can only temporary result in an emergent, shared understanding of the 'reality' of the challenges and problems that are under investigation.

\section{What Transdisciplinarity could learn from Integrated Surveys}

Now I have argued that the case of integrated surveys can be regarded as a transdisciplinary project, I propose in this section a few contributions that this case history can make to the practice of transdisciplinarity. First, I elaborate on what could be learned from the notion of 'elasticity in perspectives' in integrated surveys that benefits finding the 'included middle' in transdisciplinarity. Then, I argue that the practice of transdisciplinarity-like integrated survey projectsis essentially social. In particular, I elaborate on the possible impact that moving between, across and even beyond established, academic disciplines might have on individual researchers.

\subsection{Finding the 'Included Middle' in Coping with Dilemmas Requires 'Elasticity in Perspectives'-Looking from Rather than at a Problem Situation}

As mentioned before, dilemmas of how to deal with mutually incompatible perspectives between actors on shared problem situations, will seriously add to the complexity of the integration of knowledge. Viewed as a transdisciplinary project, the case of integrated surveys therefore suggests that transdisciplinarity is essentially about dilemmas-in classic logic: the need to choose between mutually incompatible perspectives about what the world actually is. As we have seen before, dilemmas cannot be solved definitively but "must be re-solved; over and over again" [44]. But following Nicolescu, the logic of the 'included middle' in transdisciplinarity is all about reconciliation between pairs of mutually exclusive contradictories [11]. The question therefore is how to find that included middle or at least its best possible approximation. It seems to me that transdisciplinarity could learn from the case study of integrated surveys that the included middle be situated at the 'level of reality' of a concrete problem situation under investigation. It might be approximated as an emergent, shared and time and again negotiated and renegotiated understanding between the various actors of 'the reality' of that situation between, across and beyond their own (disciplinary) perspectives and levels of reality. Like with the required elasticity in perspectives, in order to find this approximation of the included middle, a change in direction would then probably be necessary from disciplinary looking at the problem situation into looking from it. Jointly looking from that problem situation, may not only reveal the many different facets of it but also the different actors and other stakeholders that are involved-societal actors, researchers, planners, citizens, policy and decision makers at various administrative levels. But it may also clarify what is shared in that situation and what not. This suggests that what can be considered as a shared problem situation may change over time. Hence, it seems that transdisciplinary projects are inherently ongoing, never ending processes [11]-they aim at moving 
targets.

\subsection{The Social Life of Transdisciplinary Projects-Cultural Clashes and Anxiety}

Transdisciplinary projects-including integrated surveys-where different actors are involved in finding the included middle between, across and beyond their own (disciplinary) perspectives and realities, are complex, social processes more than just being complicated. They are made up of interacting agents, whose interactions create emergent properties, structures, and patterns of behaviour (see also [48]). It requires the ability of an actor to accommodate conflicting perspectives of others "unhindered by disciplinary preoccupation" as Luning mentioned [15]. But this appears to be a thorny and sometimes unruly, process beyond intellectual challenges as the case history of integrated surveys has clearly shown. In particular, it showed a potentially problematic relation between researchers in integrating surveys and those in the established disciplinary fields.

In principal, there is no opposition between disciplinarity and transdisciplinarity. To the contrary, there is no transdisciplinarity without disciplinarity [7], [11]. Each of the participants in a transdisciplinary research project has a specific home base or background either in an academic discipline or research field, or in a practice field [8]. Moreover, as Nicolescu argues [11], the logic of transdisciplinaritythe logic of the included middle-only constraints the sphere of validity of the classical logic of the excluded middle. But the term 'discipline' not only refers to a set of coherent intellectual values and constraints like focus of study, rhetoric, paradigms, rationalities, and methods embraced by the members of a (scientific) community. Those values and constraints also define that community's disciplinary identity and how members act to the extent that those values are shared by the members of that community-"science as culture" in the words of Pinch [49]. This may create cultural barriers between the various disciplines as the British scientist and writer C. P. Snow observed [50]. He spoke of "two cultures" to distinguish between the natural sciences on the one hand, and the social sciences and humanities on the other, each having their own common attitudes, common standards and patterns of behaviour, common approaches and assumptions-two groups "who had almost ceased to communicate at all".

Transdisciplinarity implies thinking outside the disciplinary box. This requires between the actors a culture of openness and of cooperation; a culture of questioning and accepting the responses as temporary; a culture of dialogue and mutual learning [1], [47].

Members of a discipline not only share common questions, concepts, methods and standards for research, but also have common institutions such as faculties, journals, textbooks, and educational programs. Consequently, when research gets more transdisciplinary, researchers enter unfamiliar grounds for scientific knowledge production Hirsch Hadorn et al. [1]. This could create uncertainty and even anxiety for researchers about their identity, legitimacy, relevance and stature.

Understanding these group-membership issues in the relation between disciplinarity and transdisciplinarity, might benefit from similar debates within the field of information systems some fifteen years ago-what was called at the time "the anxiety discourse" [51]. These debates revolved around the concerns about the information systems field's central identity. Some saw the information technology artefact as its core subject matter whereas others thought that focus as too narrow. DeSanctis [52] argued that science revolves around important questions, not the domain per se. How members are attracted and retained in the social life of the information systems community would ultimate determine the legitimacy of the field. In a similar vein, Lyytinen and King [53] argued that the field must replace the notion of a fixed core with a metaphor of a free flowing give-and-exchange "market of ideas" in which scholars (and practitioners) exchange their views regarding important (societal) questions. They assumed that such a market of ideas may attract a different type of researchers than formal and wellestablished disciplines do and explain the choices to be made in this respect by a two-dimensional frame. The first dimension is about how one sees the academic field: primarily as a vehicle for one's career advancement or as an incidental aggregate of people with shared interests. The second dimension involves the choice of whether or not to confirm to established theoretical constructs and modes of inquiry in the academic field. These two dimensions constitute a two-by-two matrix. The two 'poles' of the main diagonal represent the positions of being an established or a continuously emergent academic field. In their extremes, they represent the dilemma in aca- 
demic endeavours between rigorous solidification-if not: fossilization-and creative chaos.

It can be argued that those who are relatively peripheral to any of the established, disciplines are important for keeping the overarching transdisciplinary field viable-akin to Granovetter's 'strength of weak ties' [54]. These 'peripheral' academic actors from different academic fields may develop into 'communities of practice' when sharing their practises. But academic, social life in this transdisciplinary position may be risky, especially when there are no institutions to protect and legitimate the viewpoints of boundary spanners. Over time, they may find themselves discipline wise into a cultural limbo.

\section{Discussion and Conclusions}

In this paper, I attempted to show how the idea of transdisciplinarity helped in a better understanding of integrated surveys (in Section 3) and at the same time could learn from it (in Section 4). In brief, the required elasticity in perspectives in integrated surveys has much in common with the 'included middle' in transdisciplinarity. Therefore, it would define the identity of integrated surveys as transdisciplinary avant la lettre. Moreover, integrated surveysunderstood now as a transdisciplinary project-also suggests that the included middle is situated at the level of reality of the shared problem situation that is under investigation. Its best possible approximation could be found as an emergent understanding of 'the reality' of that situation by changing the direction from disciplinary looking at the problem situation into looking from it. Finally, the case history of integrated surveys suggests that transdisciplinary projects are complex, social processes made up of interacting actors moving away from their familiar background. This could easily create anxiety about their identity, legitimacy, relevance and stature.

I will now briefly discuss what these findings and the arguments set forth in the paper could possibly mean for the discourse of transdisciplinarity. As mentioned in the introduction, some view transdisciplinarity as addressing the need for integrated knowledge from a variety of diverse perspectives in societal problem solving regarding complex societal concerns [1], [2]. I also mentioned that in the paper I follow Nicolescu [11] in that transdisciplinarity concerns that which is at once between the disciplines, across the different disciplines, and beyond all disci- plines. Although these views taken together provide a fair description of the domain of the transdisciplinary project of integrated surveys-the case study underlying the paper-, they do not describe what transdisciplinarity is. In my opinion, Nicolescu's description of transdisciplinarity that it is about reconciliation between pairs of mutually exclusive contradictories [11] does provide an adequate description. For me, I like to add that transdisciplinarity is needed when choices have to be made between these mutually exclusive contradictories-in other words: transdisciplinarity is needed in the reconciliation of dilemmas. In the paper, the focus was on the reconciliation of the dilemma of mutually incompatible perspectives on shared problem situations and on how to deal with them.

In the introduction I also mentioned that I do not view transdisciplinarity as a unified body of concepts and approaches nor a coherent theory and methodology. Nevertheless and as I have made abundantly clear, I found in Nicolescu's Methodology of Transdisciplinarity [11] and in his earlier Manifesto of Transdisciplinarity [47] some useful concepts and ideas in framing the case of integrated surveys as transdisciplinary-levels of reality and the included middle in particular. But notwithstanding these documents emphasise that transdisciplinarity should not be reduced or confined to the 'hard', exact or natural sciences, they cannot hide the fact that they basically rest on the paradoxes that quantum mechanics has created-contradictories between quantum and classic physics. Therefore and as I have mentioned before (in Section 3), I felt the need to interpret these concepts and ideas broader than in these texts. I hope not having misused them.

At first sight, it may seem that the proposed idea of finding the included middle in transdisciplinary projects through an emergent, shared and time and again negotiated and renegotiated shared understanding is simply finding a compromise between rival disciplines. But in my opinion, this is not the case. If a compromise at all, it is in the process of negotiating and renegotiating an emergent, shared understanding of 'the reality' of a concrete problem situation under investigation-"unhindered by disciplinary preoccupation" (Luning [15]). Essential in this respect is the required change in direction from disciplinary looking at that situation into looking from it. Therefore, finding the included middle could be viewed as finding a temporary compromise 
between incompatible disciplinary perspectives of various actors on the one hand and the emergent, shared understanding of the reality of that situation on the other as if that situation were an actor as well.

Finally, a few words on rigor in transdisciplinarity. When one views transdisciplinarity mainly as reconciling mutually exclusive contradictories between the worlds of classical and of quantum physics, it seems to me that the issue of rigor only depends on the rigor of the axioms on which it is founded-the logic of the included middle. It is all about fundamental, natural laws. But when transdisciplinarity is viewed as addressing the need for integrated knowledge from a variety of diverse perspectives in societal problem solving regarding complex societal concerns as in integrated surveys, the issue of rigor is less obvious. Although some have claimed-as was mentioned in the Introduction-that this integration of knowledge can be achieved only through the methods developed in the natural sciences, in the paper I followed those who argue that the natural and social sciences and the humanities all must contribute equitably. In other words, there is a need to conciliate explanatory and predictive theories on the one hand, with emphasising the particular and the situational dependent over the universal and over rules, on the other. Here, it may be instructive to consider the idea of a "social science that matters" presented by Flyvbjerg [46]. He argues that "social science never has been, and probably never will be, able to develop the type of explanatory and predictive theory that is the ideal and hallmark of natural science". Flyvbjerg therefore proposes a social science that is prudent and based on practical common sense, inspired by Aristotle's thoughts on phronesis. He offers some guidelines for such phronetic social science including: focussing on values, placing power at the core of the analysis, getting close to reality, emphasizing little things, studying cases and contexts, asking "how?" and doing narratives, and dialoguing with a polyphony of voices.

Obviously, reconciliation of mutually exclusive contradictories in such diverse situations where not everything goes according to natural laws and predictability, will be far less rigorous than situations where the sole application of the methods developed in the natural sciences would be sufficient, but in my opinion more realistic. Different levels of rigor however, will not necessarily bring different levels of transdisciplinarity as Nicolescu seems to suggest in his Methodology [11]. In my opinion, it is rather the other way around: different applications of transdisciplinarity could show different levels of rigor. Transdisciplinarity that is prudent and based on practical common sense and wisdom-in other words: transdisciplinarity that is phronetic-recognises the level of rigor that can be achieved.

\section{Acknowledgements}

This article could not have been written without the support, encouragement and interest of colleagues and students of "integrated surveys" and "integrated geoinformation management" over almost fourty years. I am grateful for their inspiring company during this journey.

Funding: This research received no external funding.

Conflicts of Interest: The author declare no conflict of interest.

\section{References}

[1] Hirsch Hadorn, G., Bradley, D., Pohl, C., Rist, S., \& Wiesmann, U. (2006). Implications of transdisciplinarity for sustainability research. Ecological Economics, 60(1), 119-128.

[2] Klein, J. T., Grossenbacher-Mansuy, W., Haberli, R., Bill, A., Scholz, R. W., \& Welti, M. (Eds.). (2001). Transdisciplinarity: joint problem solving among science, technology and society. An effective way for managing complexity. Basel: Birkhuser.

[3] Wilson, E. O. (1999). Consilience: the unity of knowledge. London: Abacus.

[4] Costanza, R. (2003). A vision of the future of science: reintegrating the study of humans and the rest of nature. Futures, 35(6), 651-671.

[5] Gibbons, M., Limoges, C., Nowotny, H., Schwartzman, S., Scott, P., \& Trow, M. (1994). The new production of knowledge: The dynamics of science and research in contemporary societies. London: Sage.

[6] Nowotny, H., Scott, P., \& Gibbons, M. (2003). Introduction: 'Mode 2' Revisited: The New Production of Knowledge. Minerva, 41(3), 179-194.

[7] Jahn, T., Bergmann, M., \& Keil, F. (2012). Transdisciplinarity: Between mainstreaming and marginalization. Ecological Economics, 79, 1-10.

[8] Pohl, C., \& Hirsch Hadorn, G. (2008). Methodological challenges of transdisciplinary research. Natures Sciences Sociétés, 16, 111-121. 
[9] Scholz, R. W., \& Steiner, G. (2015). Transdisciplinarity at the crossroads. Sustainability Science, 10(4), 521526.

[10] Seidl, R. (2015). A functional-dynamic reflection on participatory processes in modeling projects. Ambio, 44(8), 750-765.

[11] Nicolescu, B. (2010). Methodology of transdisciplinarity - Levels of reality, logic of the included middle and complexity. Transdisciplinary Journal of Engineering 83 Science, 1(1), 17-32.

[12] Kuhn, T. S. (1970). The Structure of Scientific revolutions (2nd ed.). Chicago: University of Chicago Press.

[13] Max-Neef, M. A. (2005). Foundations of Transdisciplinarity. Ecological Economics, 53, 5-16.

[14] Winder, N. (2003). Successes and problems when conducting interdisciplinary or transdisciplinary $(=$ integrative) research. In B. Tress, G. Tress, A. Van der Valk \& G. Fry (Eds.), Interdisciplinary and Transdisciplinary Landscape Studies: Potential and Limitations (pp. 74-90). Wageningen: Alterra Green Research.

[15] Luning, H. A. (1986). Survey integration comes of age? Enschede: ITC.

[16] Schermerhorn, W. (1976). The creation of ITC: how and why it was established. ITC Journal, 1976(4), 597-604.

[17] Schermerhorn, W. (1969). Hoe en waarom het ITC ontstond als Nederlandse bijdrage tot het wetenschappelijke ontwikkelingswerk. (In Dutch: How and why the ITC was established as Netherlands contribution to international scientific aid). Delft: ITC.

[18] Schermerhorn, W. (1974). Address by the Founder and First Director of the ITC. ITC Journal, (1), 17-23.

[19] Esman, M. J. (1988). The Maturing of Development Administration. Public Administration and Development, 8(2), 125-134.

[20] Van den Ham, A., \& Veenstra, J. (2004). Shifting Logic in Area Development Practices. Aldershot, Hampshire, UK: Ashgate.

[21] Rey, P. (1968). General report. In P. Rey (Ed.), Aerial surveys and integrated studies - Proceedings of the Toulouse Conference, 21-28 September 1964 (pp. 565-567). Paris: UNESCO.

[22] Rey, P. (Ed.). (1968). Aerial surveys and integrated studies - Proceedings of the Toulouse Conference, 21-28 September 1964. Paris: UNESCO.

[23] Christian, C. S., \& Stewart, G. A. (1968). Methodology of integrated surveys. In P. Rey (Ed.), Aerial surveys and integrated studies - Proceedings of the Toulouse Conference, 21-28 September 1964 (pp. 233-280). Paris: UNESCO.
[24] Vink, A. P. A. (1966). Integrated Surveys and Land Classification. Delft: ITC-UNESCO Centre for Integrated Surveys.

[25] Mohrmann, J. C. J. (1966). Operational Planning of Integrated Surveys in Developing Countries. Delft: ITC-UNESCO Centre for Integrated Surveys.

[26] Bakker, A. J. (1971). Trends and Developments in Integrated Surveys. In J. J. Nossin (Ed.), Proceedings ITC/UNESCO Seminar on Promotion and Training Aspects of Integrated Surveys (pp. 115-123). Enschede: ITC-UNESCO Centre for Integrated Surveys.

[27] Nossin, J. J. (1975). Multi-Disciplinary Surveys and the Integration Necessary to their Fullfilment in Development Planning ITC Journal, 1975(4), 429443.

[28] Schulze, F. E. (1973). Integrated surveys and development planning. ITC Journal, 1973(2 Special Issue), 325-339.

[29] Van den Broek, J. M. M. (1971). Study and Education in Integrated Surveys. In J. J. Nossin (Ed.), Proceedings ITC/UNESCO Seminar on Promotion and Training Aspects of Integrated Surveys (pp. 125-144). Enschede: ITC-UNESCO Centre for Integrated Surveys.

[30] Hajer, M. A., \& Wagenaar, H. (Eds.). (2003). Deliberative policy analysis; understanding governance in the network society. Cambridge, U.K.: Cambridge University Press.

[31] Nossin, J. J. (1977). An integrated survey of the region Sousse, Tunisia. ITC Journal, 1977(2), 336357.

[32] Mohrmann, J. C. J. (1973). Planning and Management of Integrated Surveys for Rural Development, (Vol. XII: Integrated Surveys). Enschede: ITCUNESCO Centre for Integrated Surveys.

[33] De Man, W. H. E. (1978). Linear programming as a supporting technique in integrated surveys. ITC Journal, 1978(4), 573-594.

[34] Van der Veen, A. (2007). Spatial integrated assessment as a concilient excercise? Enschede: ITC.

[35] Kannegieter, A. (1973). New course at ITC: Photointerpretation for rural surveys. ITC Journal, 1973(1), 187-189.

[36] Whyte, R. O. (1976). Land and Land Appraisal. The Hague: Junk/Springer Netherlands.

[37] Gibson, J. J. (1986). The ecological approach to visual perception. Hillsdale, NJ: Lawrence Erlbaum Associates.

[38] Smith, B., \& Mark, D. M. (2001). Geographical categories: An ontological investigation. Intern. Journal of GIS, 15(7), 591-612. 
[39] Smith, B., \& Mark, D. M. (2003). Do mountains exist? Towards an ontology of landforms. Environment $\mathcal{E}$ Planning B (Planning and Design), 30(3), 411-427.

[40] Geertz, C. (1957). Ethos, World-View and the Analysis of Sacred Symbols. The Antioch Review, 17(4), 421-437.

[41] Thomas, W. I. (1928). The Methodology of Behavior Study (Chapter 13) In W. I. Thomas \& D. S. Thomas (Eds.), The Child in America: Behavior Problems and Programs (pp. 553-576). New York: Alfred A. Knopf.

[42] Peters Guarín, G. (2008). Integrating local knowledge into GIS-based flood risk assessment; the case of Triangulo and Mabolo communities in Naga City, The Philippines. Unpublished PhD-thesis, ITC, Enschede.

[43] Scott, J. (1998). Seeing like a state: how certain schemes to improve the human condition have failed. New Haven: Yale University Press.

[44] Rittel, H. W. J., \& Webber, M. M. (1973). Dilemmas in a general theory of planning. Policy Sciences, 4(4), 155-169.

[45] Hilhorst, D. (2004). Chapter 4 Complexity and Diversity: Unlocking Social Domains of Disaster Response. In G. Bankoff, G. Frerks \& D. Hilhorst (Eds.), In Mapping vulnerability; disasters, development and people, (pp. 52-66). London: Earthscan.

[46] Flyvbjerg, B. (2001). Making Social Science Matter. Why social inquiry fails and how it can succeed again. Cambridge UK: Cambridge University Press.

[47] Nicolescu, B. (2002). Manifesto of Transdisciplinarity (K.-C. Voss Trans.). Albany NY: State University of New York Press.

[48] Mitleton-Kelly, E. (2003). Ten Principles of Complexity and Enabling Infrastructures. In E. MitletonKelly (Ed.), Complex Systems and Evolutionary Perspectives on Organisations: The Application of Complexity Theory to Organisations, (pp. 21-52). London: Pergamon.

[49] Pinch, T. (1990). The Culture of Scientists and Disciplinary Rhetoric. European Journal of Education, 25(3), 295-304.

[50] Snow, C. P. (1965). The two cultures: and a second look. Cambridge: Cambridge University Press.

[51] King, J. L., \& Lyytinen, K. (2004). Reach and grasp. MIS Quarterly, 28(4), 539-551.

[52] DeSanctis, G. (2003). The Social Life of Information Systems Research. A Response to Benbasat and Zmud's Call for Returning to the IT Artifact. Journal of the Association for Information Systems, 4(7), 360-376.
[53] Lyytinen, K., \& King, J. L. (2004). Nothing At The Center?: Academic Legitimacy in the Information Systems Field. Journal of the Association for Information Systems, 5(6), 220-246.

[54] Granovetter, M. S. (1973). The Strength of Weak Ties. The American Journal of Sociology, 78(6), 1360-1380.

\section{About the Author}

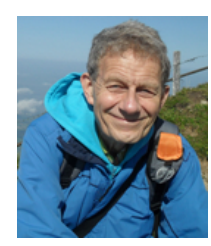

Willem Hendrik (Erik) de Man (1943) received his diploma as Engineer in Land surveying in 1967 from the (now) University of Applied Sciences, Utrecht, the Netherlands. In the same year he joined the International Training Centre for Aerial Survey (ITC) in Delft. [Since 2010, the ITC is as the Faculty of Geo-Information Science and Earth Observation part of the University of Twente, Enschede, The Netherlands.] Initially, he worked on socalled 'block-adjustments' in photogrammetric projects as well as on simulation studies of shipping traffic through canal locks. After the ITC moved to Enschede in the early 1970s, he joined its Integrated Surveys team. Here, he was involved and pioneered in the development of so-called geographic information systems (GIS). Initially, the emphasis was on design and technical aspects of GIS but gradually his focus shifted to their organizational and institutional context. In 1982-1984 he coordinated for UNESCO an international project to arrive at guidelines for establishing GIS.

From 1974 onwards, Erik studied aspects of rural development in Tunisia, Scotland, Kenya, Thailand, Bhutan and the Philippines. From 1985-1994 he was involved in several GIS projects in Thailand and in the P.R. of China in support of rural development and nature conservation, and for UNESCO at the Arab Center for the Studies of Arid Zones and Dry Lands (ACSAD). From 1974-1984 he was also elected member of local government councils of (subsequently) the municipality of Enschede and the region of Twente.

In 1996, Erik received his PhD-degree from the University of Twente on the dissertation Surveys: Information as Norm (in Dutch), a study about exploration into the institutionalization of (frequently held) village surveys in Thailand and in the Philippines. From then on, his research and teaching interests expanded to spatial data infrastructures and helped bringing concepts of culture and institutionalization, actor-network theory, complexity, and transdisciplinarity through various publications into this emerging field. In 2008 Erik retired from the ITC but continued publishing on these topics. 